\title{
Knowledge Regarding Early Detection of Cancer among Romanian Women having Relatives with Cancer
}

\author{
Lucia Maria Lotrean$^{1 *}$, Roxana Ailoaiei ${ }^{1}$, Monica Popa ${ }^{1}$, Hein de Vries ${ }^{2}$
}

\begin{abstract}
Cancers can be detected in early stages through awareness of suspicious symptoms or by specific actions undertaken by individuals or participation in medical checks or screening programmes. The present research had three objectives: to assess the knowledge of Romanian women who have relatives with cancer with regard to cancer symptoms and detection methods; to identify socio-demographics factors influencing their level of knowledge; provide information regarding the attitudes of women from the study regarding medical help-seeking in case of any symptom which might be associated with cancer. This cross-sectional study was performed in an oncological hospital from Cluj-Napoca, Romania. It involved 160 women aged 18-70 years, who had relatives with cancer. An anonymous questionnaire was filled in by the participants. The results showed that around $10 \%$ of the study sample recognized all the 8 listed symptoms associated with cancer and all the 7 listed methods for cancer detection. The results of the linear regression analyses show that the level of knowledge regarding both symptoms and methods for detection was higher among younger women $(B=-0.390, p<0.01$, respectively $B=-0.260 ; p<0.01)$, among those living in urban areas $(B=0.872, p<0.01$, respectively $B=0.676 ; p<0.01)$ and those having higher educational level $(B=0.883, p<0.001$, respectively $B=0.536 ; p<0.001)$. The majority of the participants agreed with the importance of looking for medical help within weeks up to one month in case that a symptom which might be associated with cancer was observed. The study underlines the necessity that much more information should be given to women who have relatives with cancer about what they can do to detect cancer in an early stage. This is especially needed for older women, women living in rural areas and women having a lower educational level.
\end{abstract}

Keywords: Cancer detection - knowledge - women having relatives with cancer - Romania

Asian Pac J Cancer Prev, 16 (3), 1091-1095

\section{Introduction}

Early detection of cancer greatly increases the chances for successful treatment and thus for survival. Early diagnosis is particularly relevant for cancers of the breast, cervix, skin, mouth, larynx, colon and rectum (World Health Organization, 2014).

Cancers can be detected by awareness of suspicious symptoms (passive detection) or by specific actions undertaken by individuals or participation to medical checks or screening programmes (active detection). Early symptoms of cancer include lumps in the breast or other parts of the body, sores that fail to heal, abnormal bleeding from any orifice of the body, persistent indigestion or difficulty in swallowing, nagging coughing and hoarseness, unexplained weight loss, appearance or change in a wart or mole (de Nooijer et al., 2004; Keeney et al., 2014; World Health Organization, 2014; Singapore Cancer Society, 2014).

Some symptoms are specifically associated with a particular type of cancer, while others may be caused by several types of cancer or other diseases. A major problem with the interpretation of these symptoms is the non specific nature of many of the warning signals in apparently healthy people. Hence possible cancer symptoms may be easily attributed to common diseases and medical check could be delayed. Recognizing possible warning symptoms of cancer and taking prompt action leads to early diagnosis. Different organizations underline the importance of identifying these symptoms and recommend that a physician should be consulted immediately or within a few weeks (de Nooijer et al., 2004; Gultekin et al., 2011; Yilmaz et al., 2013; World Health Organization, 2014; Singapore Cancer Society, 2014).

At the same time, several types of cancer can be detected in asymptomatic people by mean of self examination like breast self examination and examination of the skin as well as regular check-ups and physical examination by a physician and screening tests. Screening refers to the use of simple tests across a healthy population in order to identify individuals who have disease, but do not yet 
have symptoms. Examples include breast cancer screening using mammography, cervical cancer screening using cytology screening methods, including Pap smears and colo-rectal cancer screening using faecal immunochemical test or colonoscopy (de Nooijer et al., 2004; Palmer et al., 2007; Gultekin et al., 2011; Andreeva et al., 2013; Yilmaz et al., 2013; World Health Organization, 2014; Singapore Cancer Society, 2014).

Studies from different countries showed that increased awareness of possible warning symptoms of cancer and methods of early diagnoses among physicians, nurses and other health care providers as well as among the general public, can have a great impact on the disease (de Nooijer et al., 2004; Akhta et al., 2008; Akhal et al., 2010; Chin Che et al., 2011; International Agency for Research on Cancer, 2012; Luszczynska et al., 2012; Al-Sharbatti et al., 2013; Kamzol et al., 2013; Grimes et al., 2014; World Health Organization, 2014; Singapore Cancer Society, 2014). Nevertheless, in Romania there are few information with regard to the level of knowledge of different population groups regarding these issues.

Hence, this paper has three objectives. The first one is to assess the knowledge of Romanian women who have relatives with cancer with regard to cancer symptoms and detection methods. Second, it intends to identify sociodemographics factors which might influence their level of knowledge. Third, it aims to get information regarding the attitude of the women from the study regarding medical help seeking in case of any symptom which might be associated with cancer.

\section{Materials and Methods}

\section{Sample and procedure}

The study was performed between October 2010-February 2011 in the state oncological institute, Ion Chiricuta' from Cluj-Napoca, a town with approximately 330000 inhabitants from North-West Romania. It offer medical care to oncological patients from North-West Romania and, sometimes, also from other Romanian regions. Institutional approval for the study was obtained from the hospital directorate. The study involved female first degree relatives of patients diagnosed with various types of cancer, who came to different departments of oncological institute (Surgery, Radiotherapy, Chemotherapy, Oncological pediatry) for treatment or medical checks. The study subjects were contacted for participation in the study during their presence in the oncological institute for accompanying or visiting their cancer relatives (Lotrean et al., 2013).

Informed oral consent for participation was obtained from all participants. A number of 160 women were included in the study (the refusal rate was $8.5 \%$ ).

They were asked by a member of the research team to fill in a self-administered anonymous questionnaire, which investigated several components of their lifestyle as well as knowledge regarding cancer prevention and detection. Each participant filled in the questionnaire and the member of the research team collected it.

\section{Measures}

This study relies on several questions which were developed based on a questionnaire used previously in a Dutch study (de Nooijer et al., 2004). They have got information regarding demographics characteristics (age, educational level, residence in urban or rural area), level of knowledge regarding symptoms of cancer, level of knowledge regarding methods for cancer detection and attitude regarding medical help seeking behaviour in case of having a symptom which might suggest cancer. The level of knowledge about cancer symptoms was evaluated with one question; participants were asked to choose from a list the symptoms they thought that could be related to cancer. Another question assessed the level of knowledge about cancer detection, the participants being asked to choose from a list the methods they know to contribute to cancer detection.

At the same time, the study sample were asked to indicate if they would have a symptom of cancer how quick they will address this problem to a physician (less than one week; more than one week, but less than one month; one month; more than one month; only if the symptom is getting worst).

\section{Analyses}

First, data analysis included basic descriptive statistics of the respondents with regard to socio-demographics characteristics.

Second, the percentages of women who identified each symptom of cancer, respectively each method for cancer detection were calculated.

Third, two new variables were created: one variable was the number of symptoms identified by each participant (minimum0-maximum8), the other was the number of methods for cancer detection identified by each woman (minimum 0-maximum 7). Percentages of participants who identified all symptoms or less (from 0 to 7 ), respectively all detection methods or less (from 0-to 6) were calculated.

Fourthly, univariate linear regression analyses were used to assess the socio-demographics factors associate with higher level of knowledge regarding cancer related symptoms and methods for cancer detection. The dependent variables were the number of symptoms identified by each participant, respectively the number of methods for cancer detection identified by each woman. Independent variables were age, residence in rural (0) or urban area (1), educational level (0-low, 1-medium, 2-high).

Fifthly, there were included descriptive statistics of the respondents with regard to attitudes regarding medical help seeking behaviour in case of a presence of a symptom which might be associated with cancer.

Data were analysed using SPSS 20.0 statistical program. Significant results are reported at $\mathrm{p}<0.05$.

\section{Results}

\section{Socio-demographic characteristics}

The study involved 160 women having relatives with cancer with age between 18-70 years, mean age 42 $(\mathrm{SD}=12.8)$. The educational level of the sample was as 
following: $15.6 \%$ with low educational level (only junior high school or less), $42.5 \%$ with medium educational level (only high school), $41.9 \%$ with high educational level (university studies). A percentage of $38.1 \%$ of the women were living in rural areas, and $61.9 \%$ from urban areas.

\section{Knowledge regarding symptoms of cancer}

Table 1 presents the results regarding the cancer symptoms mentioned by the respondents. The symptoms which were more frequently mentioned by the participants were thickenings or lumps, unusual weight loss and abnormal bleeding, which were known by more than two thirds of the women. All the other symptoms were known by less than $40 \%$ of the study sample, the percentage varying between $20.6 \%$ for swallowing problems and $36.9 \%$ for sores that do not heal. Moreover, Table 3 shows that only around $10 \%$ of the participant recognised all the 8 symptoms of cancer, while $60 \%$ of the participants identified maximum 4 cancer symptoms.

The results of the linear regression analyses pointed out that younger women $(B=-0.390, p<0.01)$, persons from urban areas $(\mathrm{B}=0.872, \mathrm{p}<0.01)$ and those having higher educational level $(\mathrm{B}=0.883, \mathrm{p}<0.001)$ had statistically

Table 1. Knowledge Regarding Symptoms Associated with Cancer

\begin{tabular}{lc}
\hline Cancer symptoms & Percentages \\
\hline Nagging cough or hoarseness & $25.00 \%$ \\
Sores that do not heal & $36.90 \%$ \\
Appearance or change of a wart or mole & $27.50 \%$ \\
Swallowing problems & $20.60 \%$ \\
Thickenings or lumps in the breast or other & $85.60 \%$ \\
parts of the body & \\
Abnormal bleeding from any orifice of the body & $66.20 \%$ \\
Change in bowel habits & $32.50 \%$ \\
Unusual weight loss & $72.50 \%$ \\
\hline
\end{tabular}

Table 2. Knowledge Regarding Methods for Cancer Detection

\begin{tabular}{lc}
\hline Methods for cancer detection & Percentages \\
\hline Breast self examination & $69.30 \%$ \\
Skin examination & $15.60 \%$ \\
Regular medical check- ups & $68.70 \%$ \\
Having a Pap test & $75 \%$ \\
Having a mammography & $71.80 \%$ \\
Checking for the presence of blood in the stool & $33.10 \%$ \\
Colonoscopy & $43.10 \%$ \\
\hline
\end{tabular}

Table 3. Number of Cancer Symptoms and Number of Methods for Cancer Detection Recognised by the Participants

\begin{tabular}{lrcc}
\hline $\begin{array}{l}\text { No. of cancer } \\
\text { symptoms }\end{array}$ & Percentages & $\begin{array}{c}\text { No. of methods for } \\
\text { cancer detection }\end{array}$ & Percentages \\
\hline 0 & $6.20 \%$ & 0 & $5.60 \%$ \\
1 & $14.30 \%$ & 1 & $6.30 \%$ \\
2 & $12.50 \%$ & 2 & $15.00 \%$ \\
3 & $13.80 \%$ & 3 & $8.10 \%$ \\
4 & $19.40 \%$ & 4 & $20 \%$ \\
5 & $11.30 \%$ & 5 & $18.10 \%$ \\
6 & $5.00 \%$ & 6 & $16.90 \%$ \\
7 & $8.10 \%$ & 7 & $10 \%$ \\
8 & $9.40 \%$ & & \\
\hline
\end{tabular}

significant higher level of knowledge with respect to cancer symptoms.

\section{Knowledge regarding methods for cancer detection}

Table 2 lists the cancer detection methods mentioned by the respondents. It show that the most recalled methods for detection of cancer were breast self examination, having a mammography and a Pap test as well as regular medical check-ups, which were known by more than two thirds of the subjects. Skin examination was mentioned by $15.6 \%$ of the women, while checking for the presence of blood in the stool and colonoscopy were known by $33.1 \%$, respectively $43.1 \%$ of the study sample.

Table 3 shows that $10 \%$ of the participants identified all the methods for cancer detection, and around half of the women mentioned a maximum 4 methods. Almost $6 \%$ of the participants were unable to recall any method for cancer detection.

The results of the linear regression analyses show that the level of knowledge regarding the detection was higher among younger ages $(B=-0.260 ; p<0.01)$, women living in urban areas $(\mathrm{B}=0.676 ; \mathrm{p}<0.01)$ and among those having a higher educational level $(\mathrm{B}=0.536 ; \mathrm{p}<0.001)$.

Attitudes regarding seeking medical help for symptoms which might suggest cancer

A percentage of $55 \%$ of the study sample declared that in case they would have a symptom which might be associated with cancer they would seek medical help in less than one week, while $22.5 \%$ would address the problem to a physician in more than one week, but less than one month and $9.3 \%$ in one month. Only $6.9 \%$ of the participants intend to consult a physician if confronted with such a problem in more than one month and $6.3 \%$ of the women only if the symptom gets worst.

\section{Discussion}

In the North-West part of Romania 351.7 people per 100,000 of the population were diagnosed with cancer in the 2008. The most common types of cancer among women were breast cancer followed by cervix, colo-rectal, uterus, ovary, lung, stomach, tyroide, leukemias and liver cancer (Oncological Institute I Chiricuta, 2008).

This study offers information regarding the level of knowledge of Romanian women who have relatives with cancer regarding detection of cancer, as well as about their attitude regarding medical help seeking in case of a symptom which might be associated with cancer.

The results show that the majority of the participants understand the importance of looking for medical help within weeks up to one month in case that a symptom which might be associated with cancer is observed.

Nevertheless, only around $10 \%$ recognised all 8 listed symptoms. More than two thirds of the women knew that symptoms like thickenings or lumps in the breast or other parts of the body, bleeding, unusual weight loss might be associated with cancer, but other cancer symptoms such as nagging cough or hoarseness, swallowing problems, appearance or change in a wart or mole, were recognised to a less extent. 
At the same time, the results showed that more than two thirds of participants were familiar with methods for detection of breast and cervical cancer. This might be the result of the information and education campaign developed in Romania with respect to these issues, as well as the implementation of screening programs for cervical cancer in different regions of Romania (Oncological Institute I Chiricuta, 2008). On the other side, it might be also positively associated with the type of cancer among participants' relatives, since the participants might be more aware about methods for diagnoses used for this particular type of cancer. The breast and cervical cancer are the most common types of cancer among women and thus it is conceivable that many participants had relatives with these pathologies. Nevertheless, since this information was not included in the questionnaire, we can not confirm this hypothesis.

On the other side, much fewer participants recognised the methods for detection of colo-rectal cancer (less than $44 \%$ ) and skin cancer (less than 16\%). One explanation could be the fact the in Romania there are less information and education actions with respect to these issues than for breast and cervical cancer, while no screening programs are available for these types of cancers.

Moreover, only $10 \%$ recognised all listed methods for detection. The level of knowledge regarding both symptoms and methods for detection was lower among older women, among those living in rural areas and having lower educational level. These results are similar with studies from other developing countries investigating similar issues (Palmer et al., 2007; Kumar et al., 2011; Matejic et al., 2011; Radi, 2013; Adakan et al., 2014; Jo et al., 2014). At the same time, other studies from Romania also underlined the gap between different groups with respect to health related knowledge and health literacy among Romanian population based on residence and educational level (Stativa and Anghelescu, 2005; Center for Health Policies and Services, 2007; Eurobarometru, 2012).

The study is subject of several limitations. First, it did not include a national representative sample and the sample size limited the analyses of the results separately based on age, residence and education level. Second, the data relied on participants' self-reports. Although some respondents may have not reported truthfully, the likelihood of honest responses is maximized in this survey by having it conducted anonymously. Third, because of ethical issues (some of the participants' relatives might be not aware about their cancer diagnosis), the questionnaire did not include questions about the type of cancer presented among participants' relatives.

Despite these limitations, the study underline that much more information should be given to the women who have relatives with cancer about what they can do to detect cancer in an early stage. This is specially needed for older women, women living in rural areas and women having low educational level. Different channels tailored to different sections of the population should be taken into account. They include education and counselling offered by health professionals, health education materials on early detection of cancer disseminated via waiting rooms in primary health care and hospitals but also more general and non-medical media in order to reach the most disadvantaged groups of population as well (Vrscaj et al., 2008; Chukmaitov et al., 2012; Jackowska et al., 2012; Luszczynska et al., 2012; Grimes et al., 2014).

\section{Acknowledgements}

This paper was published under the frame of European Social Found, Human Resources Development Operational Programme 2007-2013, project no. POSDRU/159/1.5/S/138776

\section{References}

Adakan Y, Taskoparan M, Cekin AH, et al (2014) Implementation of screening colonoscopy amongst first- degree relatives of patients with colorectal cancer in Turkey: a cross-sectional questionnaire based survey, Asian Pac J Cancer Prev, 15, 5523-28.

Akhal LU, Celik S, Alkan I, Kurtuncu M (2010). Cancer awareness among university students in Turkey. Asian Pac $J$ Cancer Prev, 15, 4289-94.

Akhtar S, Sinha S, McKenzie S, et al (2008). Awareness of risk factor amongst first degree relative patients with colorectal cancer. Colorectal Dis, 10, 887-90.

Al-Sharbatti SS, Burhanuddin Shaikh R, Mathew E, et al (2013). Breast self examination practice and breast cancer risk perception among female university students in Ajman. Asian Pac J Cancer Prev, 14, 4919-23.

Andreeva VA, Pokhrel P (2013). Breast cancer screening utilization among Eastern European immigrant women worldwide: a systematic literature review and a focus on psychosocial barriers. Psychooncology, 22, 2664-75.

Center for Health Policies and Services (2007). Smoking and public health in Romania. knowledge, attitudes and practices regarding tobacco use among general population. The center, Bucharest (in Romania).

Chin Che C, Coomarasamy J, Suppayah B (2014). Perception of breast health amongst Malaysian female adolescents. Asian Pac J Cancer Prev, 15, 7175-80.

Chukmaitov A, Wan TT, Menachemi N, Cashin C (2008). Breast cancer knowledge and attitudes toward mammography as predictors of breast cancer preventive behavior in Kazakh, Korean, and Russian women in Kazakhstan. Int J Public Health, 53, 123-30.

De Nooijer J, Lechner L, Candel M, de Vries H (2004). Shortand long-term effects of tailored information versus general information on determinants and intentions related to early detection of cancer. Prev Med, 38, 694-703.

Eurobarometru (2012). Attitudes of Europeans towards Tobacco http://epp.eurostat.ec.europa.eu/cache/ITY_OFFPUB/ KS-SF-12-050/EN/KS-SF-12-050-EN.PDF Accessed May 2014.

Grimes C, Wanless RS, Damonti J (2014). New models for elevating the practice and status of community-based nursing across the spectrum of cancer care in Central and Eastern Europe. Eur J Oncol Nurs, 18, 97-122.

Gultekin M, Ozgul N, Olcayto E, et al (2011). Level of knowledge among Turkish people for cancer and cancer risk factors. J Turkish Soc Obstets Gynecol, 8, 57-61.

International Agency for Research on Cancer (IARC) (2012). Latest world cancer statistics. Available at: http://www.iarc. fr/en/media-centre/pr/2013/pdfs/pr223_E.pdf. Accessed Jan 2013.

Jackowska M, von Wagner C, Wardle J, et al (2012). Cervical 
screening among migrant women: a qualitative study of Polish, Slovak and Romanian women in London, UK. $J$ Fam Plann Reprod Health Care, 38, 229-38.

Jo HS, Kwon MS, Jung SM, Bo L (2014). Awareness of cancer and cancer screening by Korean community residents. Asian Pac J Cancer Prev, 15, 5523-8.

Kamzol W, Jaglarz K, Tomaszewski KA, Puskulluoglu M, Krzemieniecki K (2013).Assessment of knowledge about cervical cancer and its prevention among female students aged 17-26 years. Eur J Obstet Gynecol Reprod Biol, 166, 196-203.

Keeney S, McKenna H, Fleming P, McIlfatrick S (2011). An exploration of public knowledge of warning signs for cancer. Eur J Oncol Nurs, 15, 31-7.

Kumar YS, Mishra G, Gupta S, Shastri S (2011). Level of cancer awareness among women of lower socioeconomic status in Mumbai slums. Asian Pac J Cancer Prev, 12, 1295-8.

Lotrean LM, Ailoaiei R, Torres Mejia G. (2013) Health risk behavior of Romanian adults having relatives with Cancer. Asian Pac J Cancer Prev, 14, 6465-68.

Luszczynska A, Durawa AB, Scholz U, Knoll N (2012). Empowerment beliefs and intention to uptake cervical cancer screening: three psychosocial mediating mechanisms. Women Health, 52, 162-81.

Matejic B, Vukovic D, Pekmezovic T, Kesic V, Markovic M (2011). Determinants of preventive health behavior in relation to cervical cancer screening among the female population of Belgrade. Health Educ Res, 26, 201-11.

Oncological Institute I Chiricuta (2008). Primul raport al Registrului Regional de Cancer Nord-Vest, Romania (the first report of the North-West Regional Cancer Registry, Romania). Casa Cartii de Stiinta, Cluj-Napoca.

Palmer RC, Emmons KM, Fletcher RH, et al (2007). Familial risk and colorectal cancer screening health beliefs and attitudes in an insured population. Prev Med, 45, 336-41.

Radi SM (2013). Breast cancer awareness among Saudi females in Jeddah. Asian Pac J Cancer Prev, 14, 4307-12

Singapore Cancer Society. General Cancer Information. 8 Warning Signs and Symptoms of Cancer http://www. singaporecancersociety.org.sg/LearnAboutCancer/8warni ngssymptomsandsignsofcancer.aspx [Accesed September 2014].

Stativa E, Anghelescu C. (2005) Knowledge, attitudes and parental practices in Romania. http://www.unicef.org/ romania/ro/RAPORT_practici_parentale.pdf [Accessed September 2014].

Vrscaj MU, Vakselj A, Strzinar V, et al (2008). Knowledge about and attitudes to pap smears, cervical cancer and human papillomavirus among women in Slovenia. Eur J Gynaecol Oncol, 29,148-53.

World Health Organization. Early detection of cancer. http:// www.who.int/cancer/detection/en/. [Accesed June 2014]

Yilmaz D, Bebis H, Ortabag T (2013). Determining the awareness of and compliance with breast cancer screening among Turkish residential women. Asian Pac J Cancer Prev, 14, 3281-8. 